\title{
Bureaucratic Determinants of Foreign Policy: Some Empirical Evidence
}

\author{
By: Linda P. Brady and Charles W. Kegley, JR.
}

Brady, Linda P. and Charles W. Kegley, Jr. "Bureaucratic Determinants of Foreign Policy: Some Empirical Evidence," in International Interactions, Vol. 3, 1977.

\section{***Note: Figures may be missing for this format of the document}

\section{INTRODUCTION}

A recent development in the study of foreign policy is the growing attention being given to bureaucratic politics explanations of national foreign policy behavior.' In fact, it would be no exaggeration to characterize the bureaucratic politics approach or bureaucratic paradigm as a major research thrust in contemporary international relations theory. Foreign policy behavior, the bureaucratic perspective contends, can be accounted for best in terms of the bargaining dynamics among representatives of large-scale organizations. More specifically, the approach assumes that a nation's behavior is derived primarily from the organizations and individuals comprising the foreign policy elite who act to maximize their diverse interests and goals; thus, rather than interpreting national actions as reactions to foreign stimuli or systemic factors (Singer, 1961), advocates of the bureaucratic politics paradigm view foreign policy behavior as the consequence of decision-makers' efforts to enhance their parochial interests. Thus a researcher adopting this approach would agree with Kissinger's view "that if one wants to understand what the government is likely to do, one has to understand the bureaucratics of the problems" (Kissinger, 1973: 84). Such an explanatory framework analyzes a particular nation's foreign policy by "holding constant" domestic politics and international contextual variables as sources of national behavior and by concentrating instead on the activities of those individuals responsible for formulating the external policies of the nation. According to this perspective foreign policy decisions are not made; rather policy develops as the outcomes of bureaucratic interaction. Participating bureaucrats act to protect their personal and organizational interests, and identify national interests with these interests. Popularized by Graham Allison, the bureaucratic paradigm's influence on international relations theory can be assessed as well by the emergence of numerous critiques of that approach (Allison, 1971; Art, 1973; Allison and Halperin, 1972; Halperin and Kanter, 1973; Krasner, 1972).

Paralleling this development in international relations theory has been the emergence of event/interaction data analysis. The origins, conceptual underpinnings, and methodological assumptions of this research "movement" have been documented at length elsewhere (Burgess and Lawton, 1972; Kegley, et al., 1975; Azar and Ben-Dak, 1975). As a consequence of the availability of this type of data, there has been a change in the questions toward which foreign policy analysts direct their attention. Thus we see more cross-national, in contrast to single-case study, efforts, and more longitudinal as opposed to cross-sectional analyses (e.g., Wilkenfeld, 1973; Haas, 1974; Gamson and Modigliani, 1972). Many early criticisms of events analysis (for example, overriding concern with reliability and validity questions to the exclusion of research on substantive and/or policy-relevant problems) seem outdated, as events data analysts have shifted their focus from problems of data generation to problems of data utilization and, most significantly, to hypothesis-testing and 
model development. (See, for example, recent issues of International Interactions and the Sage International Yearbook of Foreign Policy Studies for evidence of this trend in research priorities.)

The present research is based on these dual and intimately related developments in international relations theory and empirical research. Specifically, our purpose is to utilize event/interaction data in order to conduct a preliminary empirical test of the bureaucratic politics paradigm. Our analysis makes use of data derived from two well-established events data collections-

CREON (Hermann, et al., 1973) and WEIS (McClelland and Hoggard, 1969; Martin and Young, 1968) — as well as aggregate data from various sources. CREON project data provide measures for several independent (bureaucratic structure and process) variables; WEIS project data are the major source for the measurement of our dependent (foreign policy behavior) variables. Furthermore, this test is cross-national; our data describe the bureaucratic process and foreign policy behavior of 35 nations (see Hermann, et al., 1973, for justification of the sample selection). Thus our study can be distinguished from most other analyses of bureaucratic sources of foreign policy which focus exclusively on the foreign policy process in the United States.

In short, the objectives of the present study are (1) to confront a major analytic framework with data in order to estimate its ability to explain the external behavior of nations, (2) to develop several prescriptions concerning appropriate research strategies for the construction of positive foreign policy theory, and (3) to raise some methodological questions regarding the use of event/interaction data in comparative foreign policy research.

\section{QUESTIONS OF THEORY AND DATA}

The use of events data to test the bureaucratic paradigm raises questions of both theory and data. In the first instance, the empirical verification of an analytic framework is an almost impossible methodological task. ${ }^{2}$ Although many strategies for such a task might be adopted (including, for example, a test of the major hypotheses derived from the framework), we will avoid those ambitious strategies for a simpler but more manageable test of some of the paradigm's salient assumptions and premises. More specifically, we will assess the validity of the basic assumption that aspects of the bureaucratic structure are indeed systematically related to, and potentially determinative of, variations in the behaviors states direct across national borders. By asking if bureaucratic factors account for foreign policy behavior we can estimate the explanatory power of the bureaucratic politics approach, because that approach assumes variations in national external conduct are strongly affected by the manner in which a state's bureaucracy is organized to make decisions. However, our test of this assumption must necessarily be regarded as partial and exploratory.

Second of all, characteristics of events data complicate the isolation of bureaucratic politics influences. The public sources from which events data in the main are retrieved notably lack in-depth information on bureaucratic involvement in the foreign policy decision-making process, thus making the systematic measurement of bureaucratic attributes of political systems a difficult task. Most conceptual and operational definitions of "events" prevent the identification of bureaucratic maneuvers which lack foreign targets or objects of influence. ${ }^{3}$ Consequently, information relevant to a bureaucratic politics explanation of foreign policy 
tends to be excluded from many events data collections. The bureaucratic "picture" described by these collections, therefore, often is incomplete. ${ }^{4}$ Given the nature of events data, the development of sensitive and meaningful cross-national indicators of bureaucratic decision- making structures with these data constitutes a difficult measurement problem.

Nevertheless, the problem is not insurmountable; the bureaucratic paradigm addresses theoretical questions which enable the use of events data as indicators of bureaucratic attributes. Recent critics of the paradigm argue that the notion of bureaucratic influences on foreign policy should be broadened to include dimensions of the decision structure as well as process (Art, 1973; Hermann, 1974; see also Huntington, 1961; Hilsman, 1967; and Blau, 1967, for earlier recommendations that policy analysts should focus on a wider range of influences). On their face, structural variables seem easier than process variables to identify from public sources. Thus a bureaucratic paradigm which includes both structural and process dimensions as independent variables is more suited to an events data test than a paradigm which focuses solely on the more difficult to identify process dimensions. For these reasons, the bureaucratic paradigm tested in this analysis includes both structural and process dimensions. It reflects, therefore, our belief in the theoretical validity of a broadened bureaucratic perspective.

\section{MEASURING SELECTED BUREAUCRATIC DIMENSIONS}

In order to test the impact of bureaucratic factors on foreign policy behavior, it is necessary first to identify a subset of bureaucratic politics variables presumed to exert influence, and then to operationalize these variables. As modified and expanded by Charles Hermann, the bureaucratic paradigm focuses on "the structure and process of decision and implementation used by governmental units" (Hermann, 1974). According to this conceptualization, six variable clusters comprise the essential structure and process dimensions of foreign policy making: (1) decision structure, (2) structural configuration, (3) decision process, (4) individual roles, (5) organizational properties, and (6) implementation. The seven independent variables employed in this analysis have been selected from five of these six clusters. (Structural configuration is excluded because of data availability problems.)

Decision structure variables describe the organizational context within which decisions are made. The number of individual participants in the decision has been defined as a dichotomous variable - single participant versus multiple participants - for each event. Events are then aggregated by nation. The CREON variable "single decision-maker" provides the raw data. For each nation we have calculated the percentage of that nation's events which involved a single participant. This percentage score represents the number of individual participants variable.

The decision process cluster includes those variables most frequently cited in the traditional bureaucratic politics literature. In brief, variables in this cluster describe the relationship among participants in the decision. The extent of within-government conflict' bargaining has been defined as an interval-level variable - the percentage of a nation's events in which conflict is evident. The CREON internal decision unit variables provide the raw data. We assume that the participation of bureaucratic units indicates within-government conflict or bargaining. (For elaboration and justification of this operational procedure, see Brady, 1974; 139.) Thus for each nation we have calculated the percentage of that nation's events which involved 
bureaucratic participation. Furthermore, because of the small number of events in which multiple bureaucracies participated single and multiple bureaucracy participation have not been differentiated; we assume that those events which exhibit any amount of bureaucratic participation reflect within-government conflict or bargaining.

Our third bureaucratic variable, head of state participation, describes the individual roles which appear in the decision-making process. By individual roles we mean characteristics of the participants which describe their background or their position in the organizational hierarchy. Head of state participation is a dichotomous variable - present versus absentdefined for each event and then aggregated over a nation's total events. The CREON "head of state" internal decision unit variable provides the raw data. For each nation we calculated the percentage of that nation's events in which the head of state role was involved.

Organizational properties refer to the overall government structure as well as the participating bureaucratic units. Organizational age and bureaucratic size have been selected to represent organizational properties. Both variables appear in the World Handbook of Political Social Indicators (Taylor and Hudson, 1972). Organizational age is defined as the longevity of the present continuous institutional form (variable \#291). Bureaucratic size is defined by government consumption as a percentage of gross national product (variable \#193). Unlike our other five bureaucratic variables, organizational age and bureaucratic size are not events databased measures.

The process by which decisions are implemented is the final variable cluster from which we have selected bureaucratic variables. Two variables have been included in this analysis: approval of higher authority and additional time required for implementation. Approval of higher authority is defined as a dichotomous variable for each event. Events are then aggregated by nation. This variable indicates the extent to which approval for implementation is required above the bureaucratic level at which a decision is made. The CREON variable "approval of higher authority needed" provides the raw data. For each nation we have calculated the percentage of that nation's events which require higher authority approval for implementation. Additional time required for implementation of a decision is also defined as a dichotomous variable for each event, and then aggregated by nation. The CREON variable "time required for implementation" supplies the raw data for this variable. Similar to the procedure for higher authority needed, we have calculated for each nation a percentage score based on the number of that nation's events which required additional time for implementation (i.e., beyond that required for the making of the decision).

\section{MEASURING FOREIGN POLICY OUTPUTS}

The broad range and scope of the acts states initiate in the international arena suggest why so many competing systems of policy classification exist. A complex and multidimensional phenomenon like foreign policy behavior may be identified and classified in myriad ways. Hence two significant problems for the comparative study of foreign policy concern the identification and classification of the units of analysis (Hermann, 1972). The solution of these problems require some decisions be made regarding the most relevant features of external behavior, positing which aspects of that behavior are the most significant, given our 
theoretical purpose, and subject to the most variation. Happily, a good deal of conceptual and empirical work has addressed itself to these problems (Kegley, Salmore, and Rosen, 1974; Kegley, 1973), and the findings which emerge from these investigations converge on the major distinguishing characteristics of foreign policy behavior. Basically, these studies suggest that two of the most theoretically potent dimensions to describe and classify interstate behavior are foreign policy affect and international participation. Because the bureaucratic politics paradigm itself suggests that bureaucratic attributes tend to influence these dimensions of external conduct, we will treat them as our dependent variables. ${ }^{5}$ In addition, we will include a third variable, the specificity of foreign policy, because a major assumption of the bureaucratic politics paradigm is that how a nation distributes its behavior across potential targets in the international system is determined to a large extent by the nature of the actor's foreign policy establishment. Let us discuss briefly how these variables have been conceptually and operationally defined.

Foreign policy affect refers to the amount of hostility/friendship or conflict/cooperation manifested by a state in its relations with other national actors. Hostility and cooperation are concepts often used to describe foreign policy. Not only do they appear in most traditional analyses of international politics; recent empirical studies also reveal their centrality. In general, hostility and cooperation may he defined either from the perspective of the actor or from the perspective of the target nation. The former approach is adopted here. The actor perspective evaluates the level of hostility or cooperation in terms of the actor's intention. If the actor means the action to harm the target, then hostility is expressed. Correspondingly, if the actor desires to benefit the target in some way by the action, then cooperation is expressed.

In order to operationalize foreign policy affect, we employ the World Event Interaction Survey (WEIS) data in the following fashion. The aggregate number of observed foreign policy acts of each nation in our sample for the period January 1966 through September 1969 was recorded, and the WEIS combined event categories were dichotomized as cooperative or conflictual depending on the type of event (cooperative behavior is defined as acts designated by the first eleven WEIS combined event categories, whereas conflictual behavior is indicated by the remaining eleven WEIS categories which are of a relatively hostile nature). To arrive at an index of each nation's recorded hostility and cooperation, we constructed an affect disposition index ${ }^{6}$

by summing the proportion of positive events $(+\%)$ and negative events $(-\%)$ and dividing by 100 . Thus, for example, if [a nation] has 100 events with 75 positive and 25 negative, then the disposition score... is calculated as follows:

$$
\text { Affect Disposition (AF) }=\frac{.75-.25}{100}=+.5
$$

If no events are initiated or if the positive or negative events are balanced (i.e., +.50 and -.50), the disposition measure is zero. A disposition score of zero is interpreted as "indifference" or "ambivalence."

This scale varies between +1.00 and -1.00 , with a high positive score indicating a strong propensity to engage in cooperative foreign policy actions and a high negative score indicating 
a proclivity for hostile behavior. The procedure thus enables us to compare the affect dispositions of national actors in a precise manner.

A second dimension of foreign policy behavior describes the extent to which a nation participates in the global international system. National participation is a variable which delineates a dimension of activity-passivity in international affairs, without any affective connotation. It describes the activities nations generally engage in to perpetuate ongoing and established relations and to maintain contact with other actors in the system. A rather crude but revealing indicator of national participation may be obtained by measuring the number of international organizations (ICO's) within which each nation in the system assumes formal membership. This measure may be rationalized as follows: a prime motive of decision makers in joining such voluntary associations is to provide themselves with an institutional means for maintaining contact with and interacting with other national actors; hence the degree of international participation and involvement of a nation is indicated to some extent by the level of involvement in international institutions such as intergovern mental organizations. Raw data for this indicator were obtained by recording the total number of memberships in all international organizations for each nation for the year 1965 (Taylor and Hudson, 1972: 354-56).

Our final dependent variable, the specificity of foreign policy behavior, describes the extent to which national actors concentrate or diffuse their foreign policy acts toward other national targets in the international system. The specificity-generality dimension of foreign policy is a significant but neglected component of interstate interaction which relates to the number of targets a state interacts with and the extent to which states maintain relatively enduring relationships with such foreign actors. There exists some preliminary empirical evidence which indicates both that nations are highly selective in the attention they allocate to other states (focusing their behavior on a relatively small number of targets), and that the level of specificity is subject to considerable cross-national variation (Kegley, 1975). Moreover, because it is reasonable to assert that the size of a state's foreign policy-making bureaucracy is systematically related to the manner in which it allocates its behavior across various types of recipients (McGowan, 1971), this dimension deserves our attention. Operationally, we again turned to the WEIS data to measure the specificity of external behavior, according to the following rules: (1) "active" dyadic relationships were defined operationally as those dyadic partnerships in which the initiator directed five or more acts (events) to the recipient in the period under investigation (January 1966-August 1969); this is based on the assumption that the formation of a meaningful foreign policy relationship requires some minimal level of contact and volume of interaction (Thibaut and Kelly, 1959, 64); (2) only sovereign nation-states were defined as foreign policy actors; and (3) all national actors which failed to interact with at least one other such actor a minimum of five times for this temporal span were eliminated from the sample. These rules enabled us to generate an interval- level measure of foreign policy specificity, in terms of the number of external targets.

\section{DATA ANALYSIS}

As a preliminary empirical test of the assumptions of the bureaucratic politics paradigm, we will determine the extent to which selected bureaucratic factors (our independent variables) account for variations in three dimensions of foreign policy behavior (our dependent variables). We 
assume that the paradigm's utility depends upon the ability of these bureaucratic factors to indeed exert a causal impact upon the observed external behavior of nations. If the bureaucratic politics paradigm has theoretical utility, then our evidence should demonstrate a strong association between these variables. Let us now examine the data in order to test for the presence of such co-variation.

Our procedure is a simple one: we intercorrelate the independent and dependent variables. Several features of this technique merit comment. First, given the difficulty of estimating the validity of our measures on a cross- national basis, and because of our desire to guard against systematic and random biases in the data sets, we have elected to reduce the level of measurement for all our variables to the ordinal level. We follow this procedure because we believe that a transformation of the data to an ordinal ranking of nations enhances the validity of our concepts, and that this increased confidence in our measures is worth the sacrifice of interval level information. We submit that until our events data collection and scaling procedures are improved to the point where we can contend with confidence that statements derived from the data of the sort "South Vietnam initiates twice as many acts as does Canada" possess face validity, we should employ measurement procedures which both maximize the validity of constructs and minimize the potential contamination introduced by the data source used, by coding errors, by reliability problems, and by source coverage deficiencies. Thus instead of using more powerful statistical operations on data which are questionable at best, we have rank ordered our sample population of thirty-five states and calculated Spearman rho rank-order correlation coefficients between independent and dependent variables.

Secondly, we must acknowledge that at least two types of inferential errors might be committed by this research strategy. On the one hand, although we rely on correlational analysis we want to avoid the confusion of correlation and causation. Bivariate correlation cannot establish causation. Hence the co- variations which emerge must be interpreted as bivariate contingency statements which, although useful in searching for causality prior to multivariate statistical analysis of the data and careful causal modeling (e.g., path analysis), are not definitive statements of the causal impact which one variable has upon another. Furthermore, the cross-sectional design prevents us from equating bivariate correlations with processual associations; we cannot make dynamic inferences based upon static data. Thus while our analytic procedures enable us to examine the correlation among variables, they do not permit us to determine which variations precede which.

With these reservations in mind, let us examine the evidence. Table I summarizes the (rankorder) correlations which emerge from the analysis. 


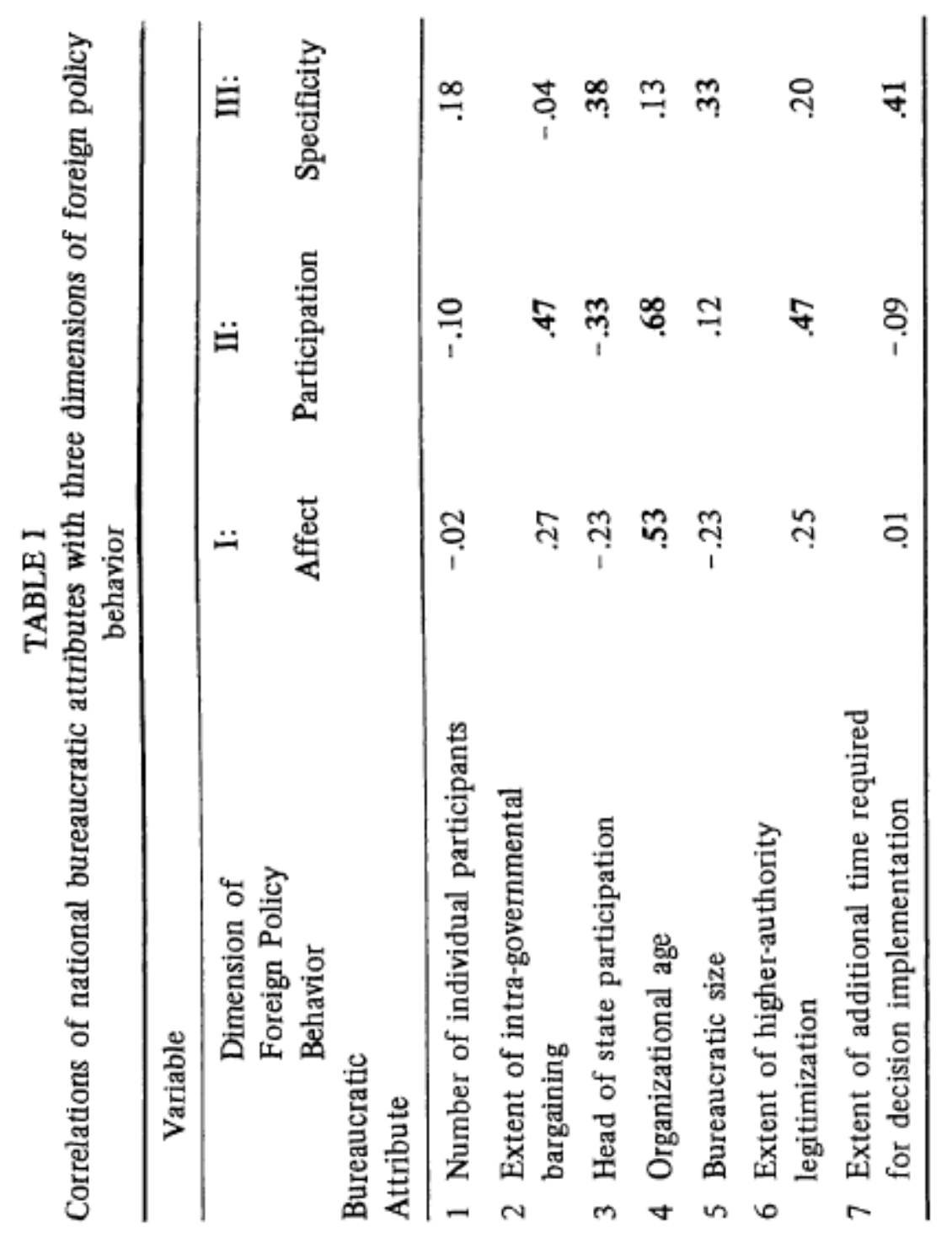

\section{INTERPRETATION: DO BUREAUCRATIC ATTRIBUTES ACCOUNT FOR FOREIGN POLICY} BEHAVIOR?

From Table 1 a number of empirical generalizations emerge concerning the bureaucratic determinants of foreign policy behavior. What follow are both a non-exhaustive summary, in propositional form, of the most conspicuous and statistically meaningful relationships found among the variables, and an identification of the more unexpected findings concerning the impact of bureaucratic politics on national foreign policy behavior.

The preceding evidence suggests the following tentative statements about bureaucratic influences on foreign policy behavior: 
1.0 Generalizations about the Dimensions of Foreign Policy Behavior Susceptible to Bureaucratic Influences

1.1 The extent of a nation's participation in the international system is strongly related to attributes of its foreign policy bureaucracy.

1.2 Foreign policy affect dispositions and specificity are only moderately associated with bureaucratic attributes.

\subsection{Bureaucratic Sources of External Behavior}

2.1 Organizational age of the foreign policy establishment goes furthest in explaining foreign policy output behavior; the more institutionalized and older the foreign policy bureaucracy, the more that state's foreign policy will be governed by continuity and inertia as opposed to discontinuity and innovation.

2.11 The temporal age of the foreign policy organization is strongly associated with the extent of a nation's involvement in the international system; the older the foreign policy establishment of a nation, the greater that nation's participation in international affairs.

2.12 The age of the foreign policy bureaucracy and its degree of institutionalization are positively correlated with the amount of foreign conflict behavior initiated by the nation; hostility is associated with older bureaucratic structures.

2.13 Organizational age exerts relatively little impact on the specificity of foreign policy behavior. The age of

the foreign policy bureaucracy has little to do with the formation and maintenance of enduring contacts with other states in the international system.

2.2 Foreign policy-making tends to be an executive affair, with power concentrated in the head-of-state. The extent of head-ofstate participation is a potent determinant of foreign policy behavior.

2.21 The less collective the decision-making process, the more formal contacts with states will be made by the executive; foreign policy specificity is determined principally by head-of-state activity.

2.22 The extent of national participatory activity is negatively correlated with the degree of head-of-state involvement in the foreign policy-making process.

2.23 External conflict behavior tends to be initiated by heads-of-state rather than collective decision-making bodies.

2.3 States which participate actively in the international arena tend to legitimize foreign policy decisions by individuals that comprise the highest echelons of the governmental structure. 
2.4 The size of the foreign policy bureaucracy fails to account for a meaningful proportion of the variation in foreign policy output behavior.

2.41 A modest positive relationship exists between bureaucratic size and the specificity of foreign policy behavior; nations with large bureaucracies (in comparison to those with relatively small foreign policy establishments) tend to maintain relations with multiple foreign targets.

2.42 Bureaucratic size is weakly associated with foreign policy affect and participation; however, there is some support for the proposition that countries with large bureaucracies (in comparison to those with relative small foreign policy establishments) tend to be more hostile in the international arena.

2.5 The extent of intra-govemmental bargaining in foreign policy decision- making, wherein decisions are the product of a process of intra-agency conflict and coalition formation, is related to the level of national involvement in the international system but unrelated to variations in foreign policy affect or specificity.

2.6 The number of individuals involved in the foreign policy decisional process is not related systematically to variations in the foreign behavior of states.

2.7 Decision time required for policy implementation affects only the specificity of a nation's external behavior. The longer the time required for implementation, the more specific is foreign policy behavior.

The foregoing evidence confirms much of the conventional wisdom regarding bureaucratic sources of foreign policy. In terms of the six variable clusters that Charles Hermann (1974) argues comprise the essential structure and process dimensions of foreign policy-making, we find strong support for the relationship between organizational properties and foreign policy behavior. Recall that organizational properties refer to the larger governmental structure, as well as to the participating bureaucratic units. Because of the strong relationships which emerge between organizational age and affect and participation, on the one hand, and bureaucratic size and specificity, on the other, we contend a broader interpretation of the bureaucratic politics paradigm is warranted.

Furthermore, the absence of a relationship between decision structure (here defined in terms of the number of individual participants) and foreign policy supports the bureaucratic politics assumption that relationships among participants are more influential than the numbers of participants per se. This helps to explain, perhaps, the strong relationship between decision process (extent of higher authority legitimization) and participation. Number of participants appears to be less salient than the bureaucratic levels from which participants are drawn. Put another way, whether the decision process requires interaction among middle and higher level bureaucrats or between middle and lower level bureaucratics influences the extent of international participation.

More striking perhaps, are the large numbers of hypothetical relationships which fail to receive support. Many of the propositions which undergird the bureaucratic politics 
paradigm were not confirmed by the evidence gathered here. The general impressions one gets from the data are that the attributes of national foreign policy bureaucracies exert only a modest impact on the external conduct of states and that they fail to account for significant proportions of the variation in foreign policy output behavior. To be sure, while several features of these bureaucracies influence external conduct to some degree, the overall impact or potency of the bureaucratic factors is rather disappointing. Clearly the evidence suggests that other factors, both internal and systemic, operate to modify the kinds of behaviors states direct across their national boundaries.

In general, we draw the following conclusions from our research. First of all, while bureaucratic factors influence some dimensions of foreign policy behavior (such as the development of institutional ties with other states in the international system), the impact varies across types of foreign policy activity. The evidence presented here suggests that bureaucratic influences explain more with respect to participation than to either affective dispositions or specificity.

Secondly, despite our inability to confirm many hypotheses relating bureaucratic influences to foreign policy behavior, we do not advocate jettisoning the entire paradigm. Indeed, the evidence partially supports bureaucratic politics explanations of foreign policy behavior. More specifically, the evidence indicates that bureaucratic influences should not be treated as a single, general explanatory factor (as many have employed it). Instead, the general cluster of bureaucratic variables should be disaggregated and these component variables should be employed to explain specific dimensions of foreign policy behavior. Accordingly, rather than viewing foreign policy actions as the results of general bureaucratic performance, a promising avenue for future research would be to attempt to explain particular dimensions of foreign policy in terms of discrete attributes of the foreign policy bureaucracy.

Moreover, it follows that our understanding of bureaucratic influences would be improved by efforts to delineate the situational conditions under which these influences operate (see Brady, 1976). The paradigm's explanatory power varies not only from one type of foreign policy behavior to another, but also from one situation to another. The organizational positions and bargaining activities of decision makers are likely to explain more adequately foreign policy behavior in crises than in more routine situations. Under conditions of crisis, participants' perceptions are less likely to be bound by their organizational positions and interests. Decision-makers respond to the common threat to national goals; they are less likely to react according to their organizational interests. To be sure, much research in this area remains to be done.

In short, the preceding suggests that we have far to go in isolating, measuring, and testing bureaucratic politics explanations of foreign policy. This is understandable given the anecdotal, descriptive, case-specific nature of most research utilizing a bureaucratic politics paradigm. At the same time, we believe that the hypotheses generated by the idiographic studies extant in the literature provide the necessary foundation for empirical studies designed to account for the role of bureaucratic variables as sources of foreign policy. Such empirical studies, therefore, are not premature. 


\section{CONCLUSION}

One of the deficiencies in the bureaucratic politics literature has been the reluctance to investigate hypotheses on a cross-national basis. It is only through cross-national study that we can derive generalizations which are not bound by time and place for their validity, and from which we can construct nomothetic theory. By employing a synchronic design, we have sought to demonstrate the utility of such an approach.

However, one of the potential hazards inherent in cross-national studies is the tendency to assume that empirically-derived generalizations are equally appropriate descriptions of the behavior of each independent national actor comprising the sample. We cannot reasonably assume that the relationships between bureaucratic attributes and foreign policy which obtain for our 35 nation sample as a collectivity are those which operate within each nation. To make such an assumption is to commit what statisticians call an ecological fallacy or what philosophers label the whole-part fallacy. Clearly, logic suggests that the discovery of general characteristics in a collectivity does not permit inferences concerning characteristics of individual members comprising the group. Consequently, this should caution us against employing descriptive generalizations we have uncovered about the impact of bureaucratic factors on foreign policy to describe the relationships which exist for particular states in the system.

We contend, in summary, that the bureaucratic politics paradigm is more complex than would be indicated by the writings of many of its advocates. Clusters of bureaucratic attributes can be identified, and these variable clusters exert differential impacts on foreign policy behavior. Furthermore, the relationship between any one cluster and foreign policy behavior varies across types of foreign policy actions. Although the theoretical utility of a bureaucratic perspective cannot be denied, the evidence reported here suggests much research remains to be done to specify the conditions under which bureaucratic influences explain foreign policy behavior.

\section{ACKNOWLEDGMENT}

We wish to acknowledge the support provided by the Department of Political Science, Goucher College and the Institute of International Studies, University of South Carolina. An earlier version of this paper was presented to the annual meetings of the International Studies Association, Washington, D.C., February 19-22, 1975.

\section{NOTES}

1. An inventory of major bureaucratic politics writings would include at least the following: Allison (1971), Allison and Halperin (1972), Art (1968, 1973), Davis (1972), Destler (1972), Halperin (1974),Halperin and Kanter (1973), Hermann (1974), Hilsman (1967), Huntington (1961), Neustadt (1960, 1970, 1973), Rourke (1972), and Schilling et al. (1962).

2. This difficulty perhaps explains the conspicuous absence of empirical tests of the major theoretical frameworks in international relations. For examples of partial tests of explanatory paradigms in foreign policy research, see Brecher, Steinberg, and Stein (1969), and Kelly, Raymond, and Rood (1973). 
3. Most conceptual and operational definitions require the explicit mention of a foreign target or object of influence. Thus actions taken within bureaucratic units in the course of decision making are not considered to be "events" unless a foreign entity can be identified.

4. The Comparative Research on the Events of Nations (CREON) project represents an exception to this general trend. CREON codes multiple bureaucratic dimensions. For extended descriptions of these variables see Hermann, et al.,1973.

5. For example, preliminary research suggests that when the bureaucratic process is centralized (as opposed to decentralized), decision makers react with a low level of hostility (high level of cooperation) (Brady, 1974: 230). Moreover, when faced with extended time and bureaucratic opposition, policy makers tend to respond cooperatively (Brady, 1974: 237).

6. This index follows the scale proposed by Burgess, Lawton, and Kridler (1972: 38). 7.

\section{REFERENCES}

- Allison, Graham T. and Morton H. Halperin (1972) "Bureaucratic Politics: a Paradigm and Some Policy Implications," in Raymond Tamer and Richard H. Ullman (eds.) Theory and Policy in International Relations. Princeton: Princeton University Press.

- Allison, Graham T. (1971) Essence of Decision: Explaining the Cuban Missile Crisis. Boston: Little, Brown, and Company.

- Art, Robert J. (1973) "Bureaucratic Politics and American Foreign Policy: a Critique." Policy Sciences. December.

- Art, Robert J. (1968) The TFX Decision. Boston: Little, Brown, and Co.

- Azar, Edward E., and Joseph Ben-Dak, eds. (1975) Theory and Practice of Events Research (New York: Gordon and Breach).

- Blau, Peter M. (1956) Bureaucracy in Modern Society. New York: Random House. Brady, Linda P. (1976) "Bureaucratic Politics and Situational Constraints in Foreign Policy," Sage International Yearbook of Foreign Policy Studies, Vol. IV (forthcoming).

- Brady, Linda P. (1977) "A Situational Approach to the Analysis of Foreign Policy," in Maurice A. East (ed.) Theoretical Bases for Comparative Foreign Policy Studies. Beverly Hills: Sage. (forthcoming).

- Brady, Linda P. (1974) Threat, Decision Time, and Awareness: The Impact of Situational Variables on Foreign Policy Behavior. Ph.D. Dissertation, The Ohio State University.

- Brecher, Michael, Blema Steinberg, and Janice Stein (1969) "A Framework for Research on Foreign Policy Behavior." Journal of Conflict Resolution XIII, No. 1.

- Burgess, Philip M. and Raymond W. Lawton (1972) "Indicators of International Behavior." Sage Professional Papers: International Studies Series 1: 02-010.

- Davis, David Howard (1972) How the Bureaucracy Makes Foreign Policy. Lexington, Mass.: D. C. Heath and Co.

- Destler, LM. (1972) Presidents, Bureaucrats, and Foreign Policy. Princeton: Princeton University Press.

- Downs, Anthony (1966) Inside Bureaucracy. Boston: Little, Brown and Company.

- East, Maurice A. (1972) "Status Discrepancy and Violence in the International System: An Empirical Analysis," in James N. Rosenau, Vincent Davis, and Maurice A. East (eds.) The Analysis of International Politics. New York: Free Press. 
- Gamson, William A., and Andre Modigliani (1971) Untangling the Cold War: A Strategy for Testing Rival Theories. Boston, Little, Brown and Company.

- Haas, Michael (1974) International Conflict. Indianapolis: Bobbs Merrill.

- Halperin, Morton H., and Arnold Kanter (1973) "The Bureaucratic Perspective: A Preliminary Framework," in Halperin and Kanter (eds.) Readings in American Foreign Policy. Boston: Little, Brown, and Company.

- Halperin, Morton H. (1974) Bureaucratic Politics and Foreign Policy, Washington, D.C.: The Brookings Institution.

- Halperin, Morton H. (1972) "Sources of Power in the Foreign Affairs Bureaucracy." MIA paper.

- Halperin, Morton H. (1970) Bureaucratic Politics and Foreign Policy. Washington: The Brookings Institution.

- Hermann, Charles F, (1977) "Bureaucratic Politics and Foreign Policy Behavior: A Theoretical Framework Using Events Data" in Maurice A. East, ed. Theoretical Bases for Comparative Foreign Policy Studies. Beverly Hills: Sage Publications, forthcoming.

- Hermann, Charles F. (1974) "Potential Variables in the Bureaucratic Politics Theoretical Perspective of Possible Utility in Explaining Foreign Behavior" CREON Summer Seminar, mimeo.

- Hermann, Charles F. (1972) "Policy Classification: A Key to the Comparative Study of Foreign Policy," in James N. Rosenau, Vincent Davis, and Maurice A. East (eds.) The Analysis of International Politics. New York: Free Press.

- Hermann, Charles F., at al. (1973) "CREON: A Foreign Events Data Set." Sage Professional Papers in International Studies 2, 02-024.

- Hermann, Charles F., Stephen A. Salmore, Maurice East, with Linda P. Brady (1973) "Code Manual for Analytical Deck of Comparative Foreign Policy Events: Revised." CREON Publication 8B.

- Hilsman, Roger (1967) To Move a Nation. New York: Doubleday.

- Huntington, Samuel P. (1961) The Common Defense. New York: Columbia Unversity Press.

- Kegley, Charles W., Jr, (1975) "Selective Attention: A General Characteristic of the Interactive Behavior of Nations." International Interactions: A Transnational Multidisciplinary Journal, forthcoming.

- Kegley, Charles W., Jr. (1973) "A General Empirical Typology of Foreign Policy Behavior." Sage Professional Papers in International Studies 02-014.

- Kegley, Charles W., Jr. et al., (eds.) (1975) International Events and the Comparative Analysis of Foreign Policy Columbia, S.C.: University of South Carolina Press.

- Kegley, Charles W., Jr., Stephen A. Salmore, and David .T. Rosen (1974) "Convergences in the Measurement of Interstate Behavior." Sage International Yearbook of Foreign Policy Studies, Vol. II, Beverly Hills: Sage Publications, pp. 309-39.

- Kissinger, Henry A. (1973) "Bureaucracy and Policymaking: The Effects of Insiders and Outsiders on the Policy Process," in Morton H. Halperin and Arnold Kanter (eds.) Readings in American Foreign Policy. Boston: Little, Brown, and Company. Krasner, Stephen D. (1972) "Are Bureaucracies Important? (or Allison Wonderland)." Foreign Policy 7: 159-179. 
- Martin W. R. and R. A. Young (1968) World Event Interaction Survey (WEIS) Program: Rules and Instructions, University of Southern California (mimeo).

- McClelland, Charles A. (1969) Working Papers of the WEIS Project, University of Southern California World Event Interaction Survey Project (mimeo).

- McClelland, Charles A., and Gary D. Hoggard (1969) "Conflict Patterns in the Interactions Among Nations," in James N, Rosenau, ed., International Politics and Foreign Policy (New York: Free Press), pp. 711-24.

- McGowan, Patrick J. and Howard B. Shapiro (1973) The Comparative Study of Foreign Policy: A Survey of Scientific Findings. Beverly Hills: Sage Publications.

- McGowan, Patrick J. (1971) Theoretical Approaches to the Comparative Study of Foreign Policy. Ph.D. Dissertation, Northwestern University.

- Neustadt, Richard E. (1973) "White House and Whitehall" in Morton H. Halperin and Arnold Kanter, eds. Readings in American Foreign Policy: A Bureaucratic Perspective. Boston: Little, Brown and Co.

- Neustadt, Richard E. (1970) Alliance Politics. N.Y.: Columbia University Press.

- Neustadt, Richard E. (1960) Presidential Power, N.Y.: John Wiley and Sons, Inc.

- Rosenau, James N. (1975) "A Pre-Theory of Foreign Policy," in William D. Coplin and

- Charles W. Kegley, Jr., eds., Analyzing International Relations. New York: Praeger. Rosenau, James N. (1972) "The External Environment as a Variable in Foreign Policy

- Analysis," in James N. Rosenau, Vincent Davis, and Maurice A. East (eds.) The Analysis of International Politics. New York: Free Press.

- Rosenau, James N. ed. (1969) Linkage Politics: Essays on the Convergence of National and International Systems.

- Rourke, Francis E. (1972) Bureaucratic Power in National Politics. Boston: Little, Brown, and Company.

- Schilling, Warner et al. (1962) Strategy, Politics, and Defense Budgets. N.Y.: Columbia University Press.

- Scott, William A. (1955) "Reliability of Content Analysis: the Case of Nominal Scale Coding." Public Opinion Quarterly. Volume 19: 321-325.

- Simon, Herbert A. (1965) Administrative Behavior. 2nd ed. New York: Free Press.

- Singer, J. David (1961) "The Level of Analysis Problem in International Relations," World Politics, Vol. 14, No. 1 (October), pp. 77-92.

- Snyder, Richard C. (1958) "A Decision-Making Approach to the Study of Political Phenomena," in Roland Young, ed. Approaches to the Study of Politics. Evanston: Northwestern University Press.

- Taylor, Charles Lewis, and Michael C. Hudson (1972) World Handbook of Political and Social Indicators, 2nd ed. New Haven: Yale University Press.

- Thibaut, John W. and Harold H. Kelley (1959) The Social Psychology of Groups. New York: John Wiley and Sons.

- Wilkenfeld, Jonathan, ed. (1973) Conflict Behavior and Linkage Politics. New York: David McKay. 